\title{
Sex differences in brain activation patterns with mental stress in patients with coronary artery disease
}

\author{
Nicole Kasher ${ }^{1}$, Matthew T. Wittbrodt ${ }^{2}$, Zuhayr S. Alam², Bruno B. Lima ${ }^{1,3}$, Jonathon A. Nye ${ }^{4}$, Carolina Campanella ${ }^{2}$, \\ Stacy Ladd ${ }^{2}$, Muhammad Hammadah ${ }^{3}$, Amit J. Shah ${ }^{1,3,5}$, Paolo Raggi ${ }^{6}$, Arshed A. Quyyumi ${ }^{3}$, Viola Vaccarino ${ }^{1,3}$ and \\ J. Douglas Bremner $2,4,5^{*}$ iD
}

\begin{abstract}
Background: Stress is an important contributor to myocardial ischemia and the progression of coronary artery disease (CAD), and women are more susceptible than men to these effects. Little is known, however, about the neural basis of these sex differences.

Methods: We investigated sex differences in neural correlates of mental stress in a sample of 53 female and 112 male participants $(N=165)$ with $C A D$, with and without mental stress-induced myocardial ischemia $(M S I)$, during exposure to mental arithmetic tasks and public speaking stress tasks using high-resolution positron emission tomography (HR-PET) and radiolabeled water imaging of the brain.

Results: Women compared to men had significantly greater activation with stress in the right frontal $(B A 9,44)$, right parietal lobe (Area 3, 6, 40), right posterior cingulate gyrus (BA 31), bilateral cerebellum, and left temporal/fusiform gyrus (BA 37) and greater deactivation in bilateral anterior cingulate gyrus (BA 24, 32), bilateral medial frontal gyrus (BA 6, 8, 9, 10), right parahippocampal gyrus, and right middle temporal gyrus (BA 21). Women with MSI (but not those without MSI) showed significantly greater activation than men in the right posterior cingulate gyrus (BA 31) and greater deactivation in several frontal and temporal lobe areas.

Conclusion: Men and women with CAD show differences in responses to stress in brain limbic areas that regulate emotion, and these functional responses differ by MSI status. Our results suggest that the cingulate gyrus may be involved in sex differences in MSI.
\end{abstract}

\section{Introduction}

According to estimates from the Global Burden of Disease 2010 Study, mental health-related disorders and cardiovascular disease (CVD) are the leading contributors to morbidity and mortality worldwide $[1,2]$. Furthermore, mental health disorders including depression are associated with a greater incidence of coronary artery disease $(\mathrm{CAD})$ and poorer prognosis after myocardial infarction (MI) and are generally more pronounced in women than men [3-10]. Sex differences in brain and

\footnotetext{
* Correspondence: jdbremn@emory.edu

${ }^{2}$ Department of Psychiatry and Behavioral Sciences, Emory University School of Medicine, Emory University, Atlanta, GA, USA

${ }^{4}$ Department of Radiology, Emory University School of Medicine, Emory

University, Atlanta, GA, USA

Full list of author information is available at the end of the article
}

physiological responses to stress in CAD patients may represent a mechanism for these differences between men and women in the incidence, prognosis, and pathophysiology of CAD.

Clinical characteristics of CAD and mental illness differ in men and women [11]. Generally, while women younger than 65 years of age are less likely to develop CAD compared to men, once they are diagnosed with $\mathrm{CAD}$, younger women tend to have a greater number of comorbidities and cardiovascular risk factors, longer duration of hospitalization for $\mathrm{CAD}$, and greater risk of mortality within 30 days of hospitalization, even though they have less coronary atherosclerosis $[3,11-20]$.

(c) The Author(s). 2019 Open Access This article is distributed under the terms of the Creative Commons Attribution 4.0 International License (http://creativecommons.org/licenses/by/4.0/), which permits unrestricted use, distribution, and reproduction in any medium, provided you give appropriate credit to the original author(s) and the source, provide a link to the Creative Commons license, and indicate if changes were made. The Creative Commons Public Domain Dedication waiver (http://creativecommons.org/publicdomain/zero/1.0/) applies to the data made available in this article, unless otherwise stated. 
A clear distinction between women and men with CAD is that women have a higher burden of stress, depression, and anxiety [21-23]. Furthermore, recent experimental studies $[11,21,24]$ have shown that psychological stress may differentially or disproportionately affect women with CAD more than men. Mental stress-induced myocardial ischemia (MSI) is a phenomenon characterized by a demand-perfusion mismatch of the heart during a mental stress challenge $[25,26]$. MSI is associated with poorer prognosis and increased mortality among patients with CAD. In a series of studies, we have shown that MSI is more common in women with CAD, especially young women, and that the underlying mechanisms may differ in women and men [21, 24, 25, 27-29]

The neural pathways linking mental stress to CAD have only recently been the subject of investigation. Brain regions involved in emotion and cardiovascular regulation, including the medial prefrontal cortex, insula, and amygdala, have been hypothesized to play a role in MSI [11]. Increased activity in the amygdala has been linked to both exposure to early stress [30-36] and PTSD [30-41] and the development of CVD [42]. We have shown increased rostral anterior cingulate (medial prefrontal cortex) activation with stress in CAD patients with MSI [43]. Prior imaging studies in conjunction with stress have shown sex differences in brain reactivity in healthy adults in brain areas involved in emotion, including the amygdala, hippocampus, and medial prefrontal cortex [44-46]. The neural correlates of stress comparing men and women with CAD, and with and without MSI, however, are not known. The objective of the present study was to investigate sex differences in neural correlates of mental stress and MSI in male and female patients with CAD. We addressed whether there are sex-related differences in the brain's response to mental stress in patients with CAD, and whether these differences are modified by MSI. We hypothesized that women would show greater activation with stress than men in brain areas involved in modulation of emotion, fear, and peripheral autonomic and stress reactivity, including amygdala, insula, and medial prefrontal cortex (anterior cingulate), and that these differences would be more pronounced in those subjects who develop MSI.

\section{Methods}

\section{Study design}

Participants were 60 female and 126 male patients with known CAD $(N=186)$ that were participants in the larger Mental Stress Ischemia Mechanisms and Prognosis Study (MIPS). Detailed methods for the MIPS cohort were described elsewhere [47]. Briefly, 695 patients between 30 and 80 years of age with confirmed stable coronary artery disease (CAD) were prospectively enrolled between 2011 and 2014 from Emory University Hospital, Grady Memorial Hospital, and the Atlanta VA Medical Center. A clinical diagnosis of CAD was met if participants had angiographic evidence of CAD with at least one major vessel affected, a history of myocardial infarction, coronary bypass surgery or angioplasty, or a positive nuclear scan or exercise test. Patients were excluded from the current study if they had a history of a major psychiatric illness, based on the Structured Clinical Interview for the Diagnostic and Statistical Manual IV (SCID), including schizophrenia, schizoaffective, or bipolar disorder, and a recent history of alcohol or substance abuse or dependence in the past year. Patients were also excluded if they had a history of loss of consciousness exceeding $1 \mathrm{~min}$, meningitis, neurological disorder such as Parkinson's disease or dementia, chronic oral steroid use or inhaled steroid use greater than $1500 \mu \mathrm{g} /$ day, or antipsychotic, opiate, or benzodiazepine medication use within the past month. The parent study's aim, of the which this sample was a sub-group, was to over represent a history of depression so that approximately half of the sample would have depression (either current depressive episode or a Beck Depression Inventory score $>13$ ). For that reason and based on methodological considerations outlined elsewhere [48], patients currently on antidepressant medications were not excluded from the study. Patients who were positive for MSI as part of the main MIPS protocol were also oversampled for the current study, resulting in roughly equivalent rates of MSI, unlike the parent study in which we have previously reported in this same sample higher rates of MSI in women, especially younger $(<50)$ women [21]. All patients underwent mental stress testing and myocardial perfusion during rest and stress was measured with Tc-99m sestamibi and Single Photon Emission Computed Tomography (SPECT) using a standardized protocol described previously in detail [47]. All study subjects provided informed consent and the study was approved by the Emory University Institutional Review Board.

\section{Psychometric assessments}

The Structured Clinical Interview for DSM IV (SCID) [49] was administered at the baseline visit by trained personnel to establish a depression diagnosis. Sociodemographic characteristics, medical history, and medication use were collected by a research nurse using standard questionnaires, chart reviews, and in-person interviews.

\section{Mental stress testing}

Subjects underwent eight PET brain imaging scans in conjunction with mental stress and control tasks in a single 
day. Participants were asked to hold beta-adrenergic antagonists and nitrate and calcium channel blockers for a minimum of $12-24$ hours prior to mental stress testing. Subjects were scanned twice for each of the four tests (mental arithmetic control, public speaking control, mental arithmetic stress, and public speaking stress). After resting in a quiet room for $30 \mathrm{~min}$, subjects were asked to perform the neutral control tasks and then the stressful tasks, each lasting approximately $2 \mathrm{~min}$, and were scanned during each task. The order of the mental stresses was randomized. For the mental arithmetic control condition, participants were tasked with counting out loud. For the public speaking control condition, subjects discussed a neutral event. For the mental stress arithmetic task, participants were asked to solve a series of increasingly complex math problems under a time constraint and were given negative feedback regarding their performance by a white-coated staff member administering the test [50]. To ensure that all participants experienced similar stress levels independent of personal skill, the difficulty level of arithmetic problems was increased until patients incorrectly answered three consecutive math problems. For the public speaking task, participants were provided two scripted scenarios of stressful interpersonal situations and instructed to develop a speech regarding these events. They were given $2 \mathrm{~min}$ to prepare each speech and three min to present it to an audience. Subjects were told that the content and duration of their speeches would later be evaluated.

\section{Brain imaging during stress}

Subjects underwent high-resolution positron emission tomography (HR-PET) brain imaging with the highresolution research tomograph (HRRT) (CTI, Knoxville, $\mathrm{TN}$ ), with a spatial resolution of $2 \mathrm{~mm}$ [51]. There was a total of eight brain scans, two scans during each of the two control (counting aloud and recalling a neutral event) and two stress (arithmetic and public speaking) conditions. Subjects were injected with $20 \mathrm{mCi}$ of ${ }^{15} \mathrm{O}$ water $10 \mathrm{~s}$ after the beginning of each task to assess brain function.

\section{Myocardial perfusion imaging during stress}

On a separate day, subjects completed single-photon emission computed tomography (SPECT) cardiac imaging in conjunction with a public speaking task to measure myocardial perfusion at rest and with mental stress, using methods previously described as part of the MIPS protocol [47]. Patients were injected with $10-14 \mathrm{mCi}$ of [Tc-99m] sestamibi at rest, and SPECT images of the heart were acquired 30-45 min later. After resting for $30 \mathrm{~min}$, patients completed the public speaking stress task and were injected with $30-40 \mathrm{mCi}$ of [Tc-99m] sestamibi (depending on body weight) $1 \mathrm{~min}$ after beginning the task. Images were acquired 40-60 min later. Cardiac data were analyzed according to a 17-myocardial segments model and scored separately by two experienced readers, blinded to the task condition, and without prior knowledge of the subject's medical history, on a scale of 0 (normal) to 4 (no perfusion). Disagreements were resolved by consensus. Stress scores were calculated by adding numbers in rest and stress conditions and calculating the difference. Participants with a stress score of 3 or higher were determined to be positive for MSI, while those with a score lower than 3 were negative for MSI.

\section{Hemodynamic reactivity}

Hemodynamic reactivity measures were collected using an automatic oscillometric device. Measurements were recorded at baseline and during each control and mental stress task. The measurements obtained were averaged over the control and stress tasks to obtain mean control and mean mental stress measures. The mean rate pressure product during mental stress and control conditions for each subject was calculated as the product of the mean heart rate and the mean systolic blood pressure during control tasks and during mental stress tasks. Stress reactivity for systolic blood pressure, heart rate, and rate pressure product was calculated as the difference between mean mental stress and mean control measures.

\section{Data analysis}

Differences in demographic and clinical variables between men and women were assessed using two sample $t$ tests for continuous variables and Chi-square tests for categorical variables. The likelihood ratio test and twoway analysis of variance (ANOVA) were used to calculate the interaction of sex with MSI for categorical and continuous variables, respectively. Generalized linear modeling (GLM) was used to compare hemodynamic reactivity (heart rate, systolic blood pressure, and rate pressure product) between men and women, before and after adjusting for covariates. Variables sequentially added and adjusted for in the models included age, race, body mass index (BMI), history of myocardial infarction, history of heart failure, and antidepressant and beta-blocker use. Variables were selected for inclusion based on a priori considerations that they might confound the association, and they were retained if their inclusion caused at least a $10 \%$ change in the estimate for sex.

HR-PET images of brain activation and deactivation during stress in men and women with and without MSI in 
hypothesized regions (bilateral amygdala, insula, and anterior cingulate/medial prefrontal cortex) were processed using statistical parametric mapping (SPM8) software, following methods previously described $[52,53]$. All scans were realigned to the first image in the scanning session, smoothed, and normalized onto a standard brain template from the Montreal Neurological Institute (MNI). First, an individual contrast map was created to identify areas of activation (stress-rest) or deactivation (rest-stress). For the purposes of this study, all control and mental stress tasks were averaged across type. Contrast maps were then computed across between-subject factors (gender, MSI). A two-layered mask was applied to each gender difference by MSI contrast. First, an exclusive mask was applied based upon significant differences during control tasks (Additional file 1: Table S1). Second, an inclusive mask was applied based on the within-gender significant activations or deactivations (Additional file 1: Tables S2-S5) as a result of mental stress. All brain activations were controlled for African-American race, presence of depression, usage of anti-depressants, diuretics, beta-blockers, and history of heart failure. Areas of significant differences based on gender and task were displayed using mricron (nitrc.org/projects/mricron) with standard stereotactical coordinates [54]. Significance MSI and gender contrast thresholds were set at $p<0.005$ and 11 contiguous voxels in brain regions to minimize risk of Type 1 and Type 11 errors [55] with the exception being within-gender activation/deactivation maps which were family-wise error corrected given the nature of a single main effect regressor contrast using this analytical pipeline [56]. Areas of significant differences based on sex and task were displayed using SPM8 with standard stereotactical coordinates [54]. Significance thresholds were set at $p<0.005$ and 11 contiguous voxels in brain regions to minimize risk of Type 1 and Type 11 errors [55].

\section{Results}

Of the 186 individuals enrolled in the study, 7 women and 14 men were excluded due to either poor scan quality or incomplete scans. The final analysis included 53 women and 112 men with a mean ( \pm standard deviation) age of $61.2 \pm 7.7$ and $62.3 \pm 8.7$, respectively. The proportion of African-Americans was nearly twofold greater among women than men (Table 1 in the "Appendix" section). Women were also more likely to have had heart failure and major depression in their lifetime and to be treated with antidepressant, beta-blocker, and diuretic medications. All other select demographic, clinical, and lifestyle characteristics were evenly distributed among men and women in the dataset, even after stratifying for MSI status (Table 1 in Appendix).

Men and women did not differ significantly in hemodynamic reactivity to psychosocial stress testing
(Table 2 in Appendix). At baseline, women, compared to men, had significantly higher heart rate (mean \pm standard deviation, $67 \pm 10$ vs $63 \pm 10 \mathrm{bpm}, p=0.01)$ and rate pressure product $(9359 \pm 1951$ vs $8456 \pm 1661, p=0.002)$. During mental stress, women displayed greater average heart rate compared to men ( $78 \pm 13$ vs $74 \pm 13 \mathrm{bpm}$, $p=0.04)$. However, there were no statistically significant sex differences in either systolic blood pressure, heart rate or rate pressure product reactivity to mental stress in both unadjusted and adjusted models.

Women had greater baseline activity during the neutral tasks (Additional file 1: Table S1) in the occipital lobe, temporal lobe, parietal lobe, and cerebellum. To account for these differences, only areas outside of the baseline differences were considered to be altered as a result of mental stress. Across the entire sample, men and women showed different neural activation and deactivation in response to mental stress, compared to control conditions. Compared to men, women showed greater activation in the left temporal/fusiform gyrus (BA 37), right parietal lobe (BA 3, 6, 40), right frontal lobe (BA 9, 44), right posterior cingulate gyrus (BA 31), and bilateral cerebellum during mental stress compared to control tasks (Table 3 in Appendix). However, women had greater deactivation than men to mental stress testing in multiple corticolimbic and related structures, including the bilateral anterior cingulate gyrus (BA 24, 32), bilateral medial frontal gyrus (BA 6, 8, 9, 10), right parahippocampal gyrus, and right middle temporal gyrus (BA 21; Table 3 in Appendix).

Sex differences in neural reactivity to mental stress also differed by MSI status. Among participants without MSI, sex differences during stress compared to control were observed in the left cerebellum and right superior parietal lobe (Table 4 in Appendix, Fig. 1). In contrast, women with MSI showed greater activation than men with MSI with stress in many brain areas including the right posterior cingulate gyrus (BA 31), right parietal lobe (BA 3, 7, 40), bilateral frontal lobe (BA 6, 8, 9, 10, 11,44 ), left temporal lobe (BA 39), and bilateral posterior cerebellum (Table 5 in Appendix, Figs. 2 and 3). Furthermore, women with MSI also had greater deactivation with stress, relative to men with MSI, in the right middle temporal gyrus (BA 21), bilateral superior frontal gyrus (BA 6, 7, 8), bilateral middle frontal gyrus (BA 6, 8, 11), bilateral medial frontal gyrus (BA 6, 9, 10), and the bilateral inferior frontal gyrus (BA 45,47 ).

\section{Discussion}

This study showed unique patterns of brain response to stress in men and women with mental stress-induced myocardial ischemia (MSI) compared to non-MSI. Women without MSI had focal but scant increases in 


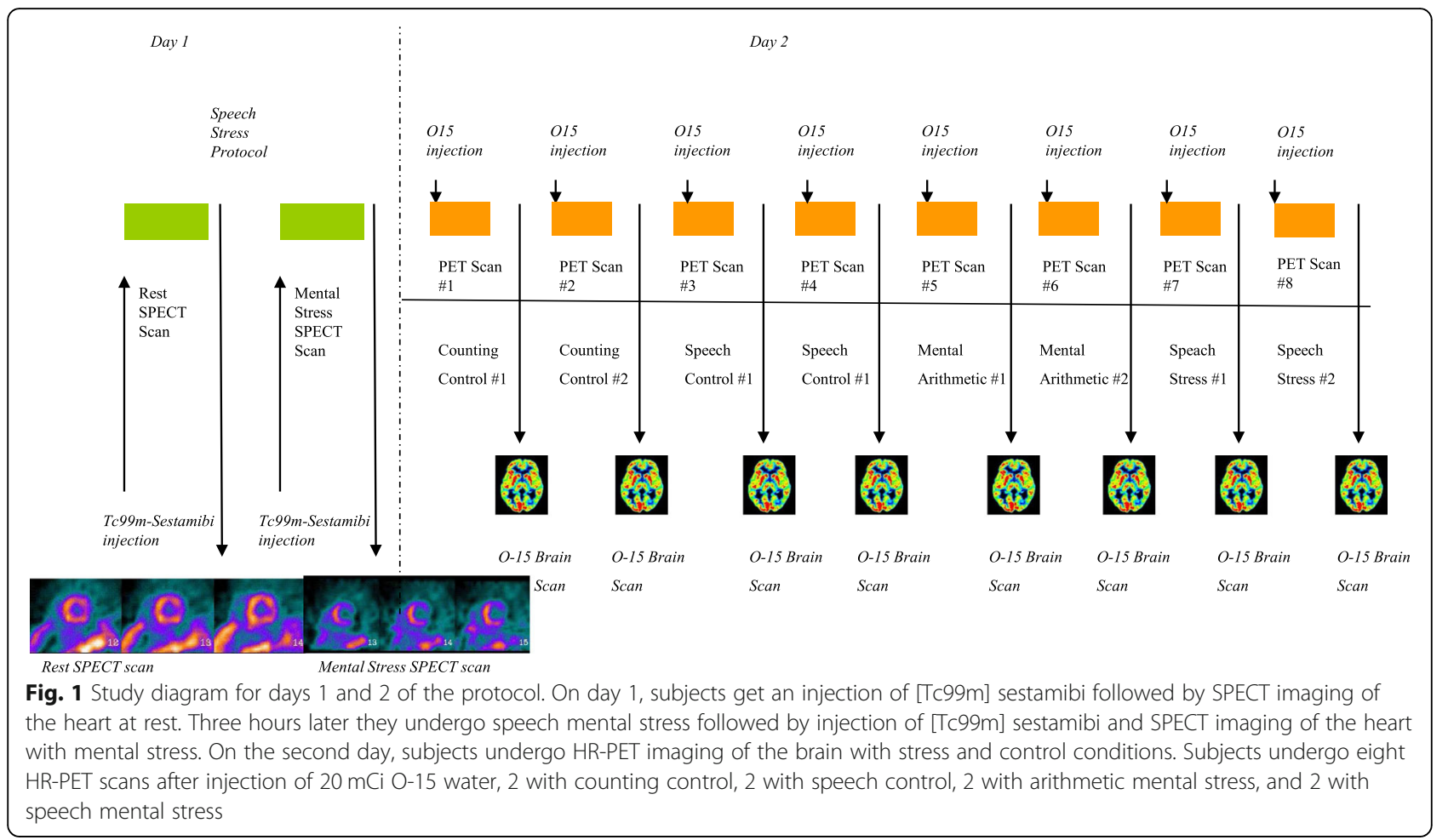

activation/deactivation compared to men without MSI. Women with MSI, however, showed widespread changes in brain activity compared to men with MSI including activation of the anterior cingulate, right parietal lobe, and bilateral frontal lobe with stress, and greater deactivations in temporal cortex, amygdala, and superior and inferior, medial, and middle frontal gyrus. These differences were seen in spite of the fact that men and women showed similar cardiovascular reactivity to stress.

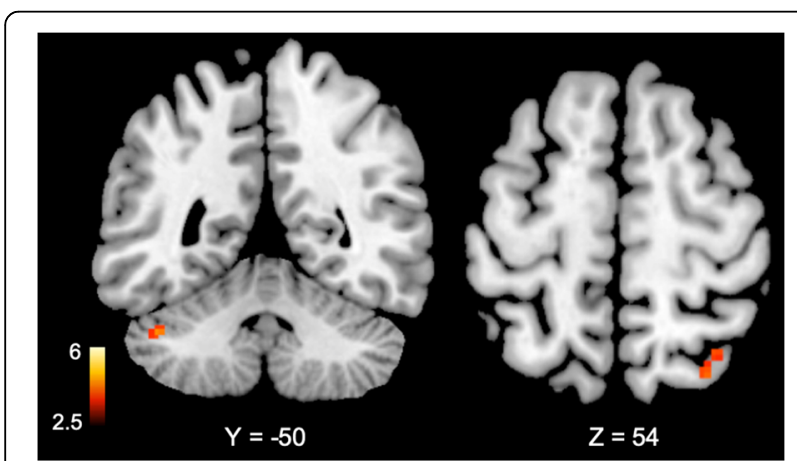

Fig. 2 Brain areas with greater $(p<0.005)$ cerebral blood flow increases (activation) during mental stress compared to control tasks in women $(n=44)$ versus men $(n=77)$ with coronary artery disease but no mental stress induced myocardial ischemia using $\left[{ }^{15} \mathrm{O}\right] \mathrm{H}_{2} \mathrm{O}$ positron emission tomography. Values below brain denote Talairach coordinates. Color bars indicate $Z$ values of activation or deactivation
The anterior cingulate plays a pivotal role in both the regulation of emotion and peripheral autonomic and cardiovascular responses to stress $[57,58]$. In addition to activating peripheral cardiovascular responses that could lead to MSI, this region is involved in the inhibition of fear responses in the amygdala and the extinction of fear [59-62]. Previous studies have shown that chronic stress alters functional reactivity of the cingulate cortex and other subsets of the limbic system to stress $[63,64]$. Studies in patients with stress-related psychiatric disorders including PTSD and depression (that have also been linked to cardiovascular disease) $[65,66]$ found decreases in stress-responsive activation in this area as well as smaller volume [67-69]. In the current study, mental stress was associated with significantly greater deactivation of the left anterior cingulate cortex in women with CAD compared to men with CAD. Greater anterior cingulate deactivations were only observed in those with MSI, as women with CAD and MSI had bilateral deactivations within the anterior cingulate compared to men with CAD.. These results suggest that dysregulation of the anterior cingulate gyrus could be involved in pathways linking mental stress to myocardial ischemia and cardiovascular-related death [70]. The results further suggest that there are differences between men and women, both in those with and without MSI. These findings may help explain why women are at 


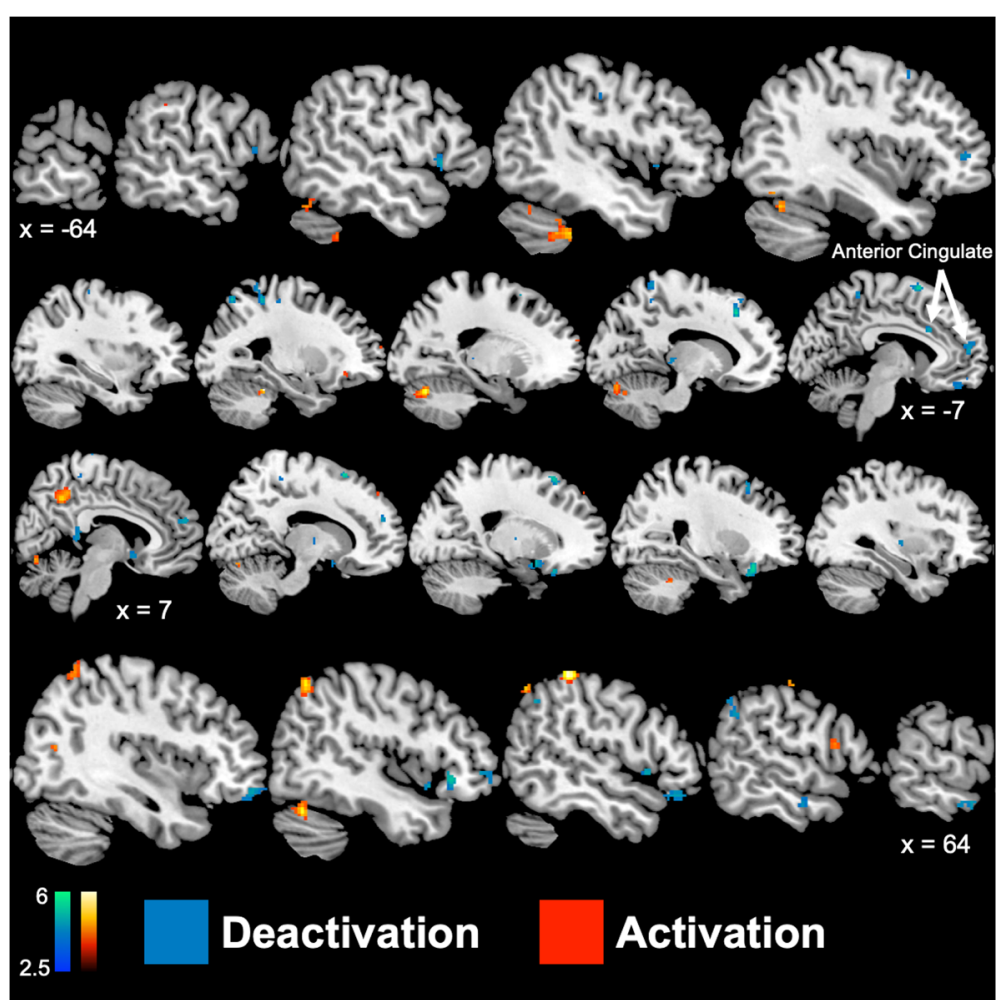

Fig. 3 Sagittal brain slices representing greater $(p<0.005)$ cerebral blood flow increases (activation; red) and decreases (deactivation; blue) during mental stress compared to control tasks in women $(n=9)$ versus men $(n=35)$ with coronary artery disease and mental stress induced myocardial ischemia using $\left[{ }^{15} \mathrm{O}\right] \mathrm{H}_{2} \mathrm{O}$ positron emission tomography. Values below brain denote Talairach $\mathrm{x}$-coordinates, where positive and negative values correspond to the right and left hemisphere, respectively. Color bars indicate $Z$ values of activation or deactivation

increased risk compared to men for both stressrelated psychiatric disorders and MSI.

Unique patterns of brain activation in women versus men with MSI could translate into differences in peripheral stress-responsive neurohormonal and cardiovascular systems. The central autonomic network contributes to the regulation of the autonomic nervous system and has sympathetic and parasympathetic system network subdivisions [71]. In the current study, stress resulted in greater deactivation in brain regions associated with sympathetic regulation (posterior and mid cingulate cortex) as well as greater activation in brain areas tied to parasympathetic regulation (cerebellum) [72, 73] in women with CAD than men with CAD. This relationship appears to occur only in those with MSI. Furthermore, the default mode network, brain regions engaged while performing passive tasks, were also more deactivated in women than men with CAD. Brain areas of the default mode network include the lateral temporal cortex and dorsal medial prefrontal cortex and are involved in functions such as introspection and exploration during low attentionrequiring tasks [74]. Our results suggest that women may have been more task-focused and less engaged in internal meditations than men in response to heightened psychosocial stress, and that mechanisms of autonomic regulation in response to stress may differ in men and women.

Men and women had many similar increases in activation and deactivation to psychosocial stress in brain regions that contribute to the execution of emotionally and cognitively stressful tasks. This included areas implicated in mental arithmetic, phonological language processing, visual processing, spatial awareness, working memory, and emotion regulation (middle frontal gyrus, superior frontal gyrus, inferior parietal lobe, supramarginal gyrus, and cingulate gyrus) [75-81]. Women with CAD, however, showed greater activation in response to mental stress in a brain region implicated in language processing (middle temporal gyrus) [78] when compared to men with CAD. Interestingly, mental stress resulted in a greater decrease in blood flow in women than men in brain regions that contributed to the regulation of language and literacy, vision and eye movement, and social cognition (right middle temporal gyrus, BA 21, medial frontal gyrus, BA 8 and 9) $[82,83]$ and most notably, anterior cingulate gyrus. 
Our study provides a foundation for the identification of neural biomarkers of mental stress in men and women with CAD. Our study, however, had limitations worth noting. Participants may have exerted themselves differently during performance of stress or control tasks and this may be a confounder. Men and women in this study differed in several variables, including race and antidepressant usage. These variables, however, may be independently associated with MSI. For instance, women have twice the rates of stress-related psychiatric disorders than men [84], and African-American women with CAD are particularly at risk [85], which may explain higher rates of antidepressant usage as well as MSI. Additionally, we have found that MSI is most common in women, and in particular younger women [24, 28, 29], with a predilection for AfricanAmerican women, a finding from the parent study of the current cohort [21]. These may represent, therefore, covariables with sex-based differences in effects of stress on the brain. The findings persisted, however, after controlling for these variables. Another limitation of this study is that the only patients with CAD were included, therefore our results are only generalizable to patient populations with CAD. The findings, however, offer suggestive evidence that differences between men and women in how brain areas modulating emotion, notably the anterior cingulate, respond to stress, may offer clues about differences in stress-induced myocardial ischemia.

\section{Perspectives and significance}

The results of this study indicate that neural correlates of mental stress differ between men and women with $\mathrm{CAD}$, with greater deactivation in women in multiple regions including the anterior cingulate gyrus, a brain region involved in emotional and autonomic regulation, compared to men. These findings related to the anterior cingulate carry over in the comparison between men and women with stress-induced myocardial ischemia. The findings suggest a possible mechanism for important differences between men and women in stress-induced myocardial ischemia, notably that women, especially younger women, may be more susceptible to this phenomenon. The clinical relevance of this is that stress-induced myocardial ischemia may require different treatment approaches than exerciseinduced ischemia, such as relaxation training, meditation, biofeedback, or other behavioral approaches. Furthermore, the worse prognosis of these patients, especially for younger women with stress-induced myocardial ischemia than for men and/or exercise-induced ischemia, illustrates the importance of focused approaches to these patients to ensure optimal outcomes.

\section{Appendix}

Table 1 Demographic and clinical characteristics of study participants by sex $(N=165)$

\begin{tabular}{|c|c|c|c|}
\hline & $\begin{array}{l}\text { Women } \\
(n=53)\end{array}$ & $\begin{array}{l}\text { Men } \\
(n=112)\end{array}$ & $P$ \\
\hline \multicolumn{4}{|l|}{ Demography } \\
\hline Age, $y \pm S D$ & $\begin{array}{l}61.2 \pm \\
7.7\end{array}$ & $\begin{array}{l}62.3 \pm \\
8.7\end{array}$ & 0.42 \\
\hline African-American, \% & $29(55)$ & $32(29)$ & 0.001 \\
\hline Education (high school) & $12(23)$ & $33(29)$ & 0.36 \\
\hline \multicolumn{4}{|l|}{ Clinical Characteristics and Lifestyle Factors } \\
\hline $\mathrm{BMI}, \pm \mathrm{SD}$ & $\begin{array}{l}31.2 \pm \\
7.4\end{array}$ & $\begin{array}{l}29.5 \pm \\
5.2\end{array}$ & 0.09 \\
\hline $\begin{array}{l}\text { Current major depressive episode, SCID, } \\
\%\end{array}$ & $17(32)$ & $24(22)$ & 0.16 \\
\hline Lifetime major depression, SCID, \% & $31(58)$ & $37(33)$ & 0.002 \\
\hline Abnormal angiogram & $37(76)$ & $66(60)$ & 0.06 \\
\hline Abnormal nuclear test & $7(14)$ & $14(13)$ & 0.79 \\
\hline Abnormal exercise test, \% & $9(18)$ & $13(12)$ & 0.27 \\
\hline Diabetes, \% & $19(36)$ & $38(34)$ & 0.81 \\
\hline Dyslipidemia, \% & $40(75)$ & $96(86)$ & 0.11 \\
\hline Heart Failure, \% & $14(26)$ & $12(11)$ & 0.01 \\
\hline Hypertension, \% & $40(75)$ & $85(76)$ & 0.95 \\
\hline Ml History, \% & $16(30)$ & $47(42)$ & 0.15 \\
\hline MSI, \% & $9(17)$ & $35(31)$ & 0.05 \\
\hline \multicolumn{4}{|l|}{ Smoking History } \\
\hline Current Smoker, \% & $7(14)$ & $16(15)$ & 0.31 \\
\hline Former Smoker, \% & $21(43)$ & $60(54)$ & \\
\hline Never Smoker, \% & $21(38)$ & $34(31)$ & \\
\hline \multicolumn{4}{|l|}{ Medication Use } \\
\hline ACE Inhibitors, \% & $21(40)$ & $52(47)$ & 0.38 \\
\hline Antidepressants, \% & $26(50)$ & $29(26)$ & 0.003 \\
\hline Aspirin, \% & $45(85)$ & $96(86)$ & 0.78 \\
\hline Beta Blockers, \% & $45(85)$ & $77(69)$ & 0.03 \\
\hline Diuretics, \% & $24(45)$ & $26(23)$ & 0.004 \\
\hline Statins, \% & $41(84)$ & $99(91)$ & 0.19 \\
\hline Vasodilators, \% & $5(9)$ & $12(11)$ & 0.79 \\
\hline
\end{tabular}

Abbreviations: SPECT single photon emission computed tomography, MSI mental stress ischemia, $B M I$ body mass index, SCID Structured Clinical Interview for DSM IV, MI myocardial infarction 
Table 2 Sex differences in hemodynamic reactivity parameters in response to mental stress, unadjusted $(N=165)$

\begin{tabular}{llll}
\hline & Women $(n=53)$ & Men (112) & $P$ \\
& Mean \pm SD & Mean \pm SD & \\
Systolic blood pressure (mmHg) & & & $135 \pm 15$ \\
Control & $140 \pm 22$ & $161 \pm 21$ & 0.07 \\
Stress & $162 \pm 27$ & $27 \pm 16$ & 0.91 \\
Systolic blood pressure reactivity & $22 \pm 17$ & & 0.07 \\
Heart rate (bmp) & & $63 \pm 10$ & 0.01 \\
Control & $67 \pm 10$ & $74 \pm 13$ & 0.04 \\
Stress & $78 \pm 13$ & $11 \pm 7$ & 0.81 \\
Heart rate reactivity & $11 \pm 9$ & & \\
Rate pressure product (mmHg*bmp) & & $8456 \pm 1661$ & $11,874 \pm 2667$ \\
Control & $9359 \pm 1951$ & $3391 \pm 2112$ & 0.002 \\
Stress & $12,676 \pm 3065$ & 0.08 \\
Rate pressure product reactivity & $3315 \pm 2155$ & 0.82 \\
\hline
\end{tabular}

SD standard deviation

"Statistical tests: Student $\mathrm{t}$ test or Wilcoxon-Mann-Whitney U test, when appropriate 
Table 3 Brain regions with significantly (one tailed $Z>2.75, p<0.005$ ) greater mental stress-induced activation or deactivation in women $(n=53)$ relative to men $(n=112)$ with coronary artery disease as measured with $\left[{ }^{15} \mathrm{O}\right] \mathrm{H}_{2} \mathrm{O}$ positron emission tomography

\begin{tabular}{|c|c|c|c|c|c|c|}
\hline \multirow{2}{*}{$\begin{array}{l}\text { Voxel } \\
\text { number }\end{array}$} & \multirow[t]{2}{*}{ Brain regions } & \multirow{2}{*}{$\begin{array}{l}\text { Brodmann's } \\
\text { area }\end{array}$} & \multicolumn{3}{|c|}{ Talairach } & \multirow{2}{*}{$\begin{array}{l}Z \\
\text { score }\end{array}$} \\
\hline & & & $\bar{x}$ & Y & Z & \\
\hline \multicolumn{7}{|c|}{ Greater stress activation in women than men } \\
\hline 22 & L cerebellum & & -26 & -40 & -18 & 5.26 \\
\hline \multirow[t]{2}{*}{86} & $\mathrm{~L}$ cerebellum & & -18 & -69 & -18 & 4.85 \\
\hline & L cerebellum & & -16 & -76 & -13 & 3.61 \\
\hline 42 & R parietal lobe, postcentral gyrus & 40 & 51 & -32 & 50 & 4.75 \\
\hline 26 & R cerebellum & & 46 & -63 & -19 & 4.25 \\
\hline 36 & R cerebellum & & 10 & -72 & -10 & 4.25 \\
\hline \multirow[t]{2}{*}{11} & R parietal lobe, postcentral gyrus & 3 & 53 & -9 & 49 & 4.13 \\
\hline & R frontal lobe, precentral gyrus & 6 & 48 & -7 & 54 & 2.82 \\
\hline \multirow[t]{2}{*}{96} & L cerebellum & & -44 & -48 & -26 & 3.87 \\
\hline & L cerebellum & & -48 & -40 & -32 & 3.52 \\
\hline \multirow[t]{2}{*}{66} & R posterior cingulate & 31 & 8 & -43 & 39 & 3.74 \\
\hline & R parietal lobe, precuneus & 7 & 4 & -51 & 38 & 3.54 \\
\hline 12 & L occipital lobe, fusiform gyrus & 19 & -42 & -65 & -9 & 3.73 \\
\hline 14 & R frontal lobe, precentral gyrus & 6 & 59 & -10 & 42 & 3.72 \\
\hline 22 & R cerebellum & & 24 & -50 & -23 & 3.56 \\
\hline \multirow[t]{2}{*}{19} & R frontal lobe, superior gyrus & 9 & 42 & 37 & 32 & 3.55 \\
\hline & R frontal lobe, middle gyrus & 9 & 42 & 46 & 26 & 2.66 \\
\hline 33 & R parietal lobe, inferior lobule & 40 & 48 & -58 & 48 & 3.53 \\
\hline \multirow[t]{2}{*}{68} & R parietal lobe, superior lobule & 7 & 30 & -59 & 53 & 3.51 \\
\hline & R parietal lobe, inferior lobule & 40 & 38 & -52 & 53 & 3.38 \\
\hline 19 & R cerebellum & & 22 & -75 & -15 & 3.47 \\
\hline 32 & L temporal lobe, fusiform gyrus & 37 & -50 & -61 & -17 & 3.44 \\
\hline 12 & R frontal lobe, precentral gyrus & 44 & 59 & 10 & 13 & 3.28 \\
\hline \multicolumn{7}{|c|}{ Greater stress deactivation in women than men } \\
\hline 23 & $\mathrm{~L}$ anterior cingulate & 24 & -4 & 23 & 24 & 5.02 \\
\hline 51 & R frontal lobe, superior gyrus & 6 & 14 & 22 & 51 & 5.00 \\
\hline \multirow[t]{2}{*}{95} & R frontal lobe, inferior gyrus & 47 & 24 & 22 & -20 & 4.67 \\
\hline & R frontal lobe, orbital gyrus & 47 & 22 & 30 & -23 & 3.07 \\
\hline \multirow[t]{2}{*}{64} & L frontal lobe, medial gyrus & 6 & -14 & 29 & 36 & 4.63 \\
\hline & L frontal lobe, superior gyrus & 8 & -10 & 32 & 47 & 3.50 \\
\hline \multirow[t]{2}{*}{86} & R frontal lobe, inferior gyrus & 47 & 44 & 27 & -8 & 4.53 \\
\hline & R frontal lobe, inferior gyrus & 47 & 50 & 28 & -13 & 4.04 \\
\hline \multirow[t]{2}{*}{46} & L frontal lobe, superior gyrus & 6 & -6 & 14 & 55 & 4.46 \\
\hline & L frontal lobe, superior gyrus & 6 & 0 & 11 & 58 & 3.25 \\
\hline \multirow[t]{2}{*}{28} & L parietal lobe, supramarginal gyrus & 40 & -63 & -43 & 27 & 4.39 \\
\hline & L temporal lobe, supramarginal gyrus & 40 & -63 & -51 & 23 & 3.35 \\
\hline 49 & L frontal lobe, inferior gyrus & & -53 & 18 & 1 & 4.06 \\
\hline 17 & L parietal lobe, superior lobule & 7 & -26 & -64 & 50 & 4.00 \\
\hline 32 & R temporal lobe, middle gyrus & 21 & 69 & -45 & -8 & 3.99 \\
\hline 37 & L parietal lobe, precuneus & 7 & -14 & -44 & 59 & 3.84 \\
\hline 26 & R frontal lobe, medial gyrus & 9 & 22 & 38 & 23 & 3.84 \\
\hline
\end{tabular}


Table 3 Brain regions with significantly (one tailed $Z>2.75, p<0.005$ ) greater mental stress-induced activation or deactivation in women $(n=53)$ relative to men $(n=112)$ with coronary artery disease as measured with $\left[{ }^{15} \mathrm{O}\right] \mathrm{H}_{2} \mathrm{O}$ positron emission tomography (Continued)

\begin{tabular}{|c|c|c|c|c|c|c|}
\hline \multirow{2}{*}{$\begin{array}{l}\text { Voxel } \\
\text { number }\end{array}$} & \multirow[t]{2}{*}{ Brain regions } & \multirow{2}{*}{$\begin{array}{l}\text { Brodmann's } \\
\text { area }\end{array}$} & \multicolumn{3}{|c|}{ Talairach } & \multirow{2}{*}{$\begin{array}{l}Z \\
\text { score }\end{array}$} \\
\hline & & & $\bar{x}$ & Y & Z & \\
\hline 34 & L frontal lobe, medial gyrus & 10 & -6 & 55 & 7 & 3.81 \\
\hline 34 & R temporal lobe, middle gyrus & 21 & 61 & -3 & -17 & 3.74 \\
\hline 11 & $\mathrm{R}$ anterior cingulate & 32 & 2 & 27 & 34 & 3.73 \\
\hline 26 & R frontal lobe, subcallosal gyrus & 34 & 18 & 7 & -12 & 3.68 \\
\hline 13 & $L$ frontal lobe, superior gyrus & 8 & 0 & 28 & 49 & 3.67 \\
\hline \multirow[t]{2}{*}{36} & R frontal lobe, medial gyrus & 10 & 10 & 55 & 17 & 3.55 \\
\hline & R frontal lobe, medial gyrus & 9 & 2 & 46 & 18 & 2.82 \\
\hline \multirow[t]{2}{*}{51} & R frontal lobe, middle gyrus & 11 & 42 & 42 & -19 & 3.54 \\
\hline & R frontal lobe, middle gyrus & 11 & 38 & 52 & -14 & 3.42 \\
\hline 31 & L parietal lobe, postcentral gyrus & 5 & -30 & -44 & 58 & 3.53 \\
\hline 14 & $\mathrm{~L}$ frontal lobe, middle gyrus & 6 & -38 & 12 & 46 & 3.53 \\
\hline 14 & $\mathrm{~L}$ frontal lobe, inferior gyrus & 45 & -59 & 18 & 6 & 3.50 \\
\hline 18 & L frontal lobe, precentral gyrus & 4 & -44 & -18 & 33 & 3.46 \\
\hline 13 & L frontal lobe, superior gyrus & 8 & -22 & 16 & 48 & 3.44 \\
\hline 24 & R frontal lobe, middle gyrus & 8 & 30 & 16 & 41 & 3.33 \\
\hline \multirow[t]{2}{*}{29} & R parietal lobe, supramarginal gyrus & 40 & 57 & -47 & 31 & 3.30 \\
\hline & $\mathrm{R}$ parietal lobe, inferior lobule & 40 & 51 & -51 & 38 & 3.15 \\
\hline 11 & L parietal lobe, precuneus & 7 & -10 & -40 & 47 & 3.27 \\
\hline 12 & R frontal lobe, medial gyrus & 10 & 2 & 54 & -9 & 3.15 \\
\hline 15 & L parietal lobe, postcentral gyrus & 3 & -28 & -23 & 46 & 3.13 \\
\hline 11 & $\mathrm{~L}$ frontal lobe, inferior gyrus & & -40 & 43 & 3 & 2.99 \\
\hline 17 & $\mathrm{~L}$ frontal lobe, middle gyrus & 11 & -38 & 50 & -14 & 2.95 \\
\hline 13 & R parahippocampal gyrus & 30 & 8 & -39 & 7 & 2.77 \\
\hline
\end{tabular}

Table 4 Brain regions with significantly (one tailed $Z>2.75, p<0.005$ ) greater mental stress-induced activation or deactivation, as measured with $\left[{ }^{15} \mathrm{O}\right] \mathrm{H}_{2} \mathrm{O}$ positron emission tomography, in women $(n=44)$ relative to men $(n=77)$ participants with CAD but not mental stress-induced myocardial ischemia

\begin{tabular}{|c|c|c|c|c|c|c|}
\hline \multirow[t]{2}{*}{ Voxel number } & \multirow[t]{2}{*}{ Brain region } & \multirow{2}{*}{$\begin{array}{l}\text { Brodmann's } \\
\text { area }\end{array}$} & \multicolumn{3}{|c|}{ Talairach } & \multirow[t]{2}{*}{ Z score } \\
\hline & & & $\bar{x}$ & Y & Z & \\
\hline \multicolumn{7}{|c|}{ Stress activation in women $>$ men } \\
\hline 13 & L cerebellum & & -44 & -50 & -34 & 3.56 \\
\hline \multirow[t]{2}{*}{17} & R parietal lobe, superior lobule & 7 & 30 & -63 & 53 & 3.19 \\
\hline & R parietal lobe, superior lobule & 7 & 34 & -56 & 55 & 3.12 \\
\hline
\end{tabular}


Table 5 Brain regions with significantly (one tailed $Z>2.75, p<0.005$ ) greater mental stress-induced activation or deactivation, as measured with $\left[{ }^{15} \mathrm{O}\right] \mathrm{H}_{2} \mathrm{O}$ positron emission tomography, in women $(n=9)$ relative to men $(n=35)$ with $\mathrm{CAD}$ and mental stress-induced myocardial ischemia

\begin{tabular}{|c|c|c|c|c|c|c|}
\hline \multirow[t]{2}{*}{ Voxel number } & \multirow[t]{2}{*}{ Brain region } & \multirow{2}{*}{$\begin{array}{l}\text { Brodmann's } \\
\text { area }\end{array}$} & \multicolumn{3}{|c|}{ Talairach } & \multirow[t]{2}{*}{$Z$ score } \\
\hline & & & $x$ & Y & Z & \\
\hline \multicolumn{7}{|c|}{ Stress activation in women $>$ men } \\
\hline 24 & $\mathrm{~L}$ cerebellum & & -26 & -40 & -18 & 5.70 \\
\hline 54 & R parietal lobe, postcentral gyrus & 40 & 51 & -32 & 50 & 5.44 \\
\hline \multirow[t]{2}{*}{112} & L cerebellum & & -18 & -69 & -18 & 5.05 \\
\hline & L cerebellum & & -14 & -76 & -13 & 3.54 \\
\hline 67 & R parietal lobe, inferior lobule & 40 & 48 & -58 & 46 & 4.97 \\
\hline 35 & R cerebellum & & 46 & -63 & -19 & 4.53 \\
\hline 33 & R cerebellum & & 10 & -72 & -10 & 4.38 \\
\hline \multirow[t]{2}{*}{112} & $\mathrm{R}$ posterior cingulate & 31 & 8 & -43 & 41 & 4.35 \\
\hline & R parietal lobe, precuneus & 7 & 4 & -51 & 38 & 4.18 \\
\hline 12 & L occipital lobe, fusiform gyrus & 19 & -42 & -65 & -9 & 4.13 \\
\hline \multirow[t]{3}{*}{110} & L cerebellum & & -46 & -38 & -32 & 4.07 \\
\hline & $\mathrm{L}$ cerebellum & & -44 & -48 & -25 & 3.33 \\
\hline & $\mathrm{L}$ cerebellum & & -53 & -44 & -35 & 3.14 \\
\hline 47 & $\mathrm{~L}$ cerebellum & & -42 & -61 & -17 & 4.02 \\
\hline 36 & R frontal lobe, inferior gyrus & 44 & 59 & 12 & 13 & 3.91 \\
\hline 14 & R temporal lobe, middle gyrus & 39 & 40 & -65 & 15 & 3.81 \\
\hline 15 & R parietal lobe, postcentral gyrus & 3 & 59 & -13 & 44 & 3.77 \\
\hline 20 & R frontal lobe, superior gyrus & 9 & 42 & 37 & 32 & 3.66 \\
\hline 15 & L frontal lobe, superior gyrus & 10 & -22 & 63 & 12 & 3.54 \\
\hline 19 & R cerebellum & & 24 & -50 & -24 & 3.54 \\
\hline 41 & R parietal lobe, inferior lobule & 40 & 38 & -52 & 53 & 3.48 \\
\hline 15 & $\mathrm{~L}$ frontal lobe, middle gyrus & 11 & -24 & 32 & -12 & 3.37 \\
\hline 13 & R frontal lobe, superior gyrus & 8 & 14 & 48 & 36 & 3.33 \\
\hline 12 & L parietal lobe, inferior lobule & 40 & -61 & -33 & 33 & 3.26 \\
\hline 14 & R cerebellum & & 22 & -75 & -15 & 3.18 \\
\hline 14 & R frontal lobe, superior gyrus & 10 & 42 & 48 & 23 & 2.89 \\
\hline \multicolumn{7}{|c|}{ Stress deactivation in women $>$ men } \\
\hline \multirow[t]{2}{*}{129} & R frontal lobe, inferior gyrus & 47 & 24 & 22 & -20 & 5.66 \\
\hline & R frontal lobe, orbital gyrus & 47 & 22 & 30 & -23 & 4.01 \\
\hline 51 & R frontal lobe, superior gyrus & 6 & 14 & 22 & 51 & 5.47 \\
\hline 37 & $\mathrm{~L}$ frontal lobe, medial gyrus & 6 & -14 & 29 & 36 & 4.95 \\
\hline \multirow[t]{2}{*}{88} & R frontal lobe, inferior gyrus & 47 & 44 & 27 & -6 & 4.94 \\
\hline & R frontal lobe, inferior gyrus & 47 & 50 & 34 & -15 & 3.80 \\
\hline 33 & L parietal lobe, supramarginal gyrus & 40 & -63 & -43 & 27 & 4.91 \\
\hline 52 & L frontal lobe, superior gyrus & 6 & -4 & 12 & 55 & 4.56 \\
\hline 24 & $\mathrm{~L}$ anterior cingulate & 24 & -4 & 23 & 24 & 4.54 \\
\hline 17 & L parietal lobe, superior lobule & 7 & -26 & -64 & 50 & 4.41 \\
\hline \multirow[t]{2}{*}{42} & R temporal lobe, middle gyrus & 21 & 69 & -45 & -8 & 4.25 \\
\hline & R temporal lobe, inferior gyrus & 20 & 67 & -47 & -15 & 2.82 \\
\hline \multirow[t]{2}{*}{69} & L parietal lobe postcentral gyrus & 40 & -26 & -38 & 49 & 4.20 \\
\hline & L parietal lobe, postcentral gyrus & 5 & -30 & -44 & 58 & 3.75 \\
\hline
\end{tabular}


Table 5 Brain regions with significantly (one tailed $Z>2.75, p<0.005$ ) greater mental stress-induced activation or deactivation, as measured with $\left[{ }^{15} \mathrm{O}\right] \mathrm{H}_{2} \mathrm{O}$ positron emission tomography, in women $(n=9)$ relative to men $(n=35)$ with CAD and mental stress-induced myocardial ischemia (Continued)

\begin{tabular}{|c|c|c|c|c|c|c|}
\hline \multirow[t]{2}{*}{ Voxel number } & \multirow[t]{2}{*}{ Brain region } & \multirow{2}{*}{$\begin{array}{l}\text { Brodmann's } \\
\text { area }\end{array}$} & \multicolumn{3}{|c|}{ Talairach } & \multirow[t]{2}{*}{$Z$ score } \\
\hline & & & $x$ & Y & $Z$ & \\
\hline \multirow[t]{2}{*}{30} & L frontal lobe, precentral gyrus & 44 & -63 & 12 & 9 & 4.17 \\
\hline & $\mathrm{L}$ frontal lobe, inferior gyrus & 45 & -59 & 18 & 6 & 3.94 \\
\hline 53 & R temporal lobe, inferior gyrus & 21 & 61 & -9 & -16 & 4.16 \\
\hline 54 & R frontal lobe, subcallosal gyrus & 34 & 16 & 7 & -14 & 4.15 \\
\hline 24 & R frontal lobe, medial gyrus & 9 & 22 & 38 & 23 & 4.04 \\
\hline 14 & L frontal lobe, superior gyrus & 8 & 0 & 28 & 49 & 3.98 \\
\hline \multirow[t]{2}{*}{53} & L frontal lobe, inferior gyrus & & -53 & 18 & 1 & 3.97 \\
\hline & $L$ frontal lobe, inferior gyrus & 47 & -46 & 14 & -1 & 3.15 \\
\hline 46 & R frontal lobe, medial gyrus & 10 & 10 & 53 & 16 & 3.97 \\
\hline \multirow[t]{2}{*}{26} & R frontal lobe, middle gyrus & 8 & 28 & 16 & 43 & 3.93 \\
\hline & R frontal lobe, middle gyrus & 8 & 24 & 22 & 46 & 3.24 \\
\hline 15 & L frontal lobe, superior gyrus & 8 & -22 & 16 & 48 & 3.83 \\
\hline \multirow[t]{2}{*}{86} & R frontal lobe, middle gyrus & 10 & 44 & 50 & -7 & 3.80 \\
\hline & $\mathrm{R}$ frontal lobe, middle gyrus & 11 & 40 & 46 & -17 & 3.63 \\
\hline 32 & $L$ thalamus & & -16 & -27 & 3 & 3.78 \\
\hline \multirow[t]{2}{*}{32} & R parietal lobe, supramarginal gyrus & 40 & 59 & -47 & 29 & 3.73 \\
\hline & R parietal lobe, inferior lobule & 40 & 51 & -52 & 38 & 3.60 \\
\hline 11 & R limbic lobe, cingulate gyrus & 32 & 2 & 27 & 34 & 3.72 \\
\hline \multirow[t]{2}{*}{30} & R temporal lobe, superior gyrus & 22 & 51 & 12 & -2 & 3.70 \\
\hline & R temporal lobe, superior gyrus & 38 & 46 & 13 & -9 & 3.62 \\
\hline 35 & L frontal lobe, paracentral lobule & 5 & -12 & -42 & 59 & 3.69 \\
\hline 31 & $\mathrm{~L}$ frontal lobe, medial gyrus & 10 & -6 & 55 & 7 & 3.64 \\
\hline 20 & R lentiform nucleus & & 16 & -7 & 5 & 3.61 \\
\hline \multirow[t]{2}{*}{34} & L frontal lobe, paracentral lobule & 5 & -6 & -38 & 52 & 3.61 \\
\hline & L parietal lobe, precuneus & 7 & -12 & -42 & 47 & 3.53 \\
\hline 51 & R posterior cingulate & 29 & 4 & -36 & 13 & 3.53 \\
\hline 12 & L frontal lobe, middle gyrus & 6 & -38 & 12 & 46 & 3.41 \\
\hline 18 & $\mathrm{R}$ anterior cingulate & 25 & 4 & 9 & -7 & 3.39 \\
\hline 14 & $\mathrm{~L}$ frontal lobe, inferior gyrus & 10 & -42 & 45 & 3 & 3.39 \\
\hline 20 & $\mathrm{~L}$ frontal lobe, precentral gyrus & 4 & -44 & -18 & 36 & 3.39 \\
\hline 12 & L frontal lobe, precentral gyrus & 4 & -36 & -24 & 55 & 3.38 \\
\hline 22 & L parietal lobe, postcentral gyrus & 3 & -30 & -27 & 42 & 3.26 \\
\hline 22 & R frontal lobe, medial gyrus & 6 & 2 & -22 & 63 & 3.25 \\
\hline \multirow[t]{2}{*}{27} & L frontal lobe, medial gyrus & 8 & -12 & 31 & 45 & 3.22 \\
\hline & $\mathrm{L}$ anterior cingulate & 32 & -10 & 22 & 44 & 3.22 \\
\hline 13 & R frontal lobe, medial gyrus & 11 & 2 & 54 & -11 & 3.20 \\
\hline 11 & R lentiform nucleus & & 32 & -13 & 2 & 3.19 \\
\hline \multirow[t]{2}{*}{17} & R frontal lobe, paracentral Lobule & 5 & 8 & -34 & 54 & 3.15 \\
\hline & R frontal lobe, paracentral lobule & 5 & 14 & -34 & 49 & 2.93 \\
\hline 21 & L frontal lobe, orbital gyrus & 11 & -6 & 44 & -19 & 3.10 \\
\hline
\end{tabular}




\section{Additional file}

Additional file 1: Additional tables. (DOCX $59 \mathrm{~kb}$ )

\begin{abstract}
Abbreviations
ANOVA: Analysis of variance; BA: Brodmann's area; BMI: Body mass index; CAD: Coronary artery disease; CVD: Cardiovascular disease; DSM-5: Diagnostic and Statistical Manual - 5; FDA: Food and Drug Administration; GLM: general linear model; HR-PET: High-resolution positron emission tomography; MI: Myocardial infarction; MNI: Montreal Neurological Institute; MRI: Magnetic resonance imaging; MSI: Mental stress ischemia; PET: Positron emission tomography; SCID: Structured Clinical Interview for DSM-5; SPECT: Singlephoton emission computed tomography; SPM8: Statistical parametric mapping -8
\end{abstract}

\section{Acknowledgements}

We acknowledge and thank Delicia Votaw, C.N.M.T., and Margie Jones, C.N.M.T., Nancy Murrah, R.N., Janice Parrott, R.N., Karen Sykes, and Steve Rhodes, R.N., for their assistance with imaging analysis, patient assessments, and clinical research.

\section{Authors' contributions}

JAN, AJS, PR, AAQ, W, and JDB contributed to the study design. JAN, AJS, PR, $A A Q, W$, and JDB obtained funding. BBL, JAN, SL, MH, AJS, PR, AAQ, W, and $J D B$ contributed to the subject recruitment, study procedures, and scanning. NK, AJS, PR, AAQ, W, and JDB contributed to the writing of the manuscript. NK, BBL, JAN, MTW, ZSA, CC, SL, MH, AJS, PR, AAQ, W, and JDB revised the manuscript. NK, BBL, JAN, MTW, ZSA, CC, MH, AJS, PR, AAQ, W, and JDB contributed to the data analysis and interpretation. All authors read and approved the final manuscript.

\section{Funding}

This research was supported by NIH research grant P01 HL101398. Additional support came from NIH grants R01 HL088726, K24 MH076955, T32 MH067547, R01 MH56120, K24 HL077506, R01 HL068630, R01 HL109413, K23 HL127251, R01 HL125246, and S10 RR16917.

\section{Availability of data and materials}

Data availability inquiries can be made to the senior author.

\section{Ethics approval and consent to participate}

This study was approved by the Emory Institutional Review Board and all subjects provided written informed consent for participation.

\section{Consent for publication}

All authors provided consent for publication.

\section{Competing interests}

The authors declare that they have no competing interests.

\begin{abstract}
Author details
${ }^{1}$ Department of Epidemiology, Rollins School of Public Health, Emory University, Atlanta, GA, USA. ${ }^{2}$ Department of Psychiatry and Behavioral Sciences, Emory University School of Medicine, Emory University, Atlanta, GA, USA. ${ }^{3}$ Department of Medicine (Cardiology), Emory University School of Medicine, Emory University, Atlanta, GA, USA. ${ }^{4}$ Department of Radiology, Emory University School of Medicine, Emory University, Atlanta, GA, USA. ${ }^{5}$ Atlanta VA Medical Center, Decatur, GA, USA. ${ }^{6}$ Mazankowski Alberta Heart Institute and the Department of Medicine, University of Alberta, Edmonton, Alberta, Canada.
\end{abstract}

Received: 26 February 2019 Accepted: 27 June 2019 Published online: 12 July 2019

\section{References}

1. Lozano R, Naghavi M, Foreman K, Lim S, Shibuya K, Aboyans V, Abraham J, Adair T, Aggarwal R, Ahn SY, et al. Global and regional mortality from 235 causes of death for 20 age groups in 1990 and 2010: a systematic analysis for the Global Burden of Disease Study 2010. Lancet. 2012;380(9859):2095-128.
2. Whiteford HA, Degenhardt L, Rehm J, Baxter AJ, Ferrari AJ, Erskine HE, Charlson FJ, Norman RE, Flaxman AD, Johns N, et al. Global burden of disease attributable to mental and substance use disorders: findings from the Global Burden of Disease Study 2010. Lancet. 2013;382(9904): 1575-86.

3. Anand SS, Islam S, Rosengren A, Franzosi MG, Steyn K, Yusufali AH, Keltai M, Diaz R, Rangarajan S, Yusuf S. Risk factors for myocardial infarction in women and men: insights from the INTERHEART study. Eur Heart J. 2008;29(7):932-40.

4. Gallo LC, Roesch SC, Fortmann AL, Carnethon MR, Penedo FJ, Perreira K, Birnbaum-Weitzman O, Wassertheil-Smoller S, Castaneda SF, Talavera GA, et al. Associations of chronic stress burden, perceived stress, and traumatic stress with cardiovascular disease prevalence and risk factors in the Hispanic Community Health Study/Study of Latinos Sociocultural Ancillary Study. Psychosom Med. 2014;76(6):468-75

5. Lagraauw HM, Kuiper J, Bot I. Acute and chronic psychological stress as risk factors for cardiovascular disease: Insights gained from epidemiological, clinical and experimental studies. Brain Behav Immun. 2015;50:18-30.

6. An K, Salyer J, Brown RE, Kao HF, Starkweather A, Shim I. Salivary ciomarkers of chronic psychosocial stress and CVD risks: a systematic review. Biol Res Nurs. 2016;18(3):241-63.

7. Lichtman JH, Froelicher ES, Blumenthal JA, Carney RM, Doering LV, FrasureSmith N, Freedland KE, Jaffe AS, Leifheit-Limson EC, Sheps DS, et al. Depression as a risk factor for poor prognosis among patients with acute coronary syndrome: systematic review and recommendations: a scientific statement from the American Heart Association. Circulation. 2014;129(12):1350-69.

8. Sanghavi M, Gulati M. Sex differences in the pathophysiology, treatment, and outcomes in IHD. Current atherosclerosis reports. 2015;17(6):511.

9. Parker $\mathrm{G}$, Brotchie H. Gender differences in depression. Int Rev Psychiatry. 2010;22(5):429-36.

10. Rosengren A, Hawken S, Ounpuu S, Sliwa K, Zubaid M, Almahmeed WA, Blackett KN, Sitthi-amorn C, Sato H, Yusuf S, et al. Association of psychosocial risk factors with risk of acute myocardial infarction in 11119 cases and 13648 controls from 52 countries (the INTERHEART study): casecontrol study. Lancet. 2004;364:953-62.

11. Vaccarino V, Bremner JD. Behavioral, emotional and neurobiological determinants of coronary heart disease risk in women. Neurosci Biobehav Rev. 2017;74(Pt B):297-309.

12. Go AS, Mozaffarian D, Roger VL, Benjamin EJ, Berry JD, Borden WB, Bravata DM, Dai S, Ford ES, Fox CS, et al. Heart disease and stroke statistics--2013 update: a report from the American Heart Association. Circulation. 2013; 127(1):e6-e245.

13. Crea F, Battipaglia I, Andreotti F. Sex differences in mechanisms, presentation and management of ischaemic heart disease. Atherosclerosis. 2015;241(1):157-68.

14. Shaw $L$, Bugiardini R, Merz CN. Women and ischemic heart disease: evolving knowledge. J Am Coll Cardiol. 2009;54(17):1561-75.

15. Izadnegahdar M, Singer J, Lee MK, Gao M, Thompson CR, Kopec J, Humphries KH. Do younger women fare worse? Sex differences in acute myocardial infarction hospitalization and early mortality rates over ten years. J Womens Health (Larchmt). 2014;23(1):10-7.

16. Ani C, Pan D, Martins D, Ovbiagele B. Age- and sex-specific in-hospital mortality after myocardial infarction in routine clinical practice. Cardiol Res Pract. 2010;2010:752765.

17. Gupta A, Mayer EA, Acosta JR, Hamadani K, Torgerson C, van Horn JD, Chang L, Naliboff B, Tillisch K, Labus JS. Early adverse life events are associated with altered brain network architecture in a sex- dependent manner. Neurobiol Stress. 2017;7:16-26.

18. Leifheit-Limson EC, D'Onofrio G, Daneshvar M, Geda M, Bueno H, Spertus JA, Krumholz HM, Lichtman JH. Sex differences in cardiac risk factors, perceived risk, and health care provider discussion of risk and risk modification among young patients with acute myocardial infarction: the VIRGO study. J Am Coll Cardiol. 2015;66(18):1949-57.

19. El-Menyar A, Ahmed E, Albinali H, Al-Thani H, Gehani A, Singh R, Al Suwaidi J. Mortality trends in women and men presenting with acute coronary syndrome: insights from a 20-year registry. PLoS One. 2013;8(7):e70066.

20. Vaccarino V, Parsons L, Peterson ED, Rogers WJ, Kiefe Cl, Canto J. Sex differences in mortality after acute myocardial infarction: changes from 1994 to 2006. Arch Intern Med. 2009:169(19):1767-74.

21. Vaccarino V, Wilmot K, Al Mheid I, Ramadan R, Pimple P, Shah AJ, Garcia EV, Nye J, Ward L, Hammadah M, et al. Sex differences in mental stress-Induced myocardial ischemia in patients with coronary heart disease. JAHA. 2016;5(9). 
22. Shah AJ, Ghasemzadeh N, Zaragoza-Macias E, Patel R, Eapen DJ, Neeland IJ, Pimple PM, Zafari AM, Quyyumi AA, Vaccarino V. Sex and age differences in the association of depression with obstructive coronary artery disease and adverse cardiovascular events. JAHA. 2014;3(3):e000741.

23. Xu X, Bao H, Strait K, Spertus JA, Lichtman JH, D'Onofrio G, Spatz E, Bucholz EM, Geda M, Lorenze NP, et al. Sex differences in perceived stress and early recovery in young and middle-aged patients with acute myocardial infarction. Circulation. 2015;131(7):614-23.

24. Vaccarino V, Shah AJ, Rooks C, Ibeanu I, Nye JA, Pimple P, Salerno A, D'Marco L, Karohl C, Bremner JD, et al. Sex differences in mental stress-induced myocardial ischemia in young survivors of an acute myocardial infarction. Psychosom Med. 2014;76(3):171-80.

25. Strike PC, Steptoe A. Systematic review of mental stress-induced myocardial ischaemia. Eur Heart J. 2003;24(8):690-703.

26. Arri SS, Ryan M, Redwood SR, Marber MS. Mental stress-induced myocardial ischaemia. Heart. 2016;102:472-80.

27. Wei J, Rooks C, Ramadan R, Shah AJ, Bremner JD, Quyyumi AA, Kutner M, Vaccarino V. Meta-analysis of mental sress-induced myocardial ischemia and subsequent cardiac events in patients with coronary artery disease. Am J Cardiol. 2014;114(2):187-92.

28. Vaccarino V, Sullivan S, Hammadah M, Wilmot K, Al Mheid I, Ramadan R, Elon L, Pimple PM, Garcia EV, Nye J, et al. Mental stress-induced-myocardial ischemia in young patients with recent myocardial infarction: sex differences and mechanisms. Circulation. 2018;137:794-805

29. Sullivan S, Hammadah M, Al Mheid I, Wilmot K, Ramadan R, Alkhoder A, Isakadze N, Shah A, Levantsevych O, Pimple PM, et al. Sex differences in hemodynamic and microvascular mechanisms of myocardial ischemia induced by mental stress. Arterioscler Thromb Vasc Biol. 2018:38(2):473-80.

30. Cisler JM, James GA, Tripathi S, Mletzko T, Heim C, Hu XP, Mayberg $H S$, Nemeroff CB, Kilts CD. Differential functional connectivity within an emotion regulation neural network among individuals resilient and susceptible to the depressogenic effects of early life stress. Psychol Med. 2013:43(3):507-18

31. van Harmelen $A L$, van Tol MJ, Demenescu LR, van der Wee NJ, Veltman DJ, Aleman A, van Buchem MA, Spinhove P, Penninx BWJH, Elzinga BM. Enhanced amygdala reactivity to emotional faces in adults reporting childhood emotional maltreatment. Soc Cogn Affect Neurosci. 2013;8:362-9

32. Shin LM, Orr SP, Carson MA, Rauch SL, Macklin ML, Lasko NB, Peters PM, Metzger LJ, Dougherty DD, Cannistraro PA, et al. Regional cerebral blood flow in the amygdala and medial prefrontal cortex during traumatic imagery in male and female Vietnam veterans with PTSD. Arch Gen Psychiatry. 2004;61(2):168-76.

33. Rauch SL, Whalen PJ, Shin LM, Mclnerney SC, Macklin ML, Lasko NB, Orr SP, Pitman RK. Exaggerated amygdala response to masked facial stimuli in posttraumatic stress disorder: a functional MRI study. Biol Psychiatry. 2000;47(9):769-76

34. Nicholson AA, Sapru I, Densmore M, Frewen PA, Neufeld RWJ, Théberge J, McKinnon MC, Lanius RA. Unique insula subregion resting-state functional connectivity with amygdala complexes in posttraumatic stress disorder and its dissociative subtype. Psychiatry Res Neuroimaging. 2016;250:61-72.

35. Lanius RA, Williamson PC, Densmore M, Boksman K, Gupta MA, Neufeld RW, Gati JS, Menon RS. Neural correlates of traumatic memories in posttraumatic stress disorder: A functional MRI investigation. Am J Psychiatry. 2001;158:1920-2.

36. Bryant RA, Felmingham $\mathrm{KL}, \mathrm{Kemp} \mathrm{AH}$, Barton M, Peduto AS, Rennie C, Gordon E, Williams LM. Neural networks of information processing in posttraumatic stress disorder: a functional magnetic resonance imaging study. Biol Psychiatry. 2005;58(2):111-8.

37. Armony JL, Corbo V, Clement MH, Brunet A. Amygdala response in patients with acute PTSD to masked and unmasked emotional facial expressions. Am J Psychiatry. 2005;162(10):1961-3.

38. Bremner JD, Vermetten $E$, Schmahl C, Vaccarino V, Vythilingam M, Afzal N, Grillon C, Charney DS. Positron emission tomographic imaging of neural correlates of a fear acquisition and extinction paradigm in women with childhood sexual abuse-related posttraumatic stress disorder. Psychol Med. 2005;35(6):791-806.

39. Britton JC, Phan KL, Taylor SF, Fig LM, Liberzon I. Corticolimbic blood flow in posttraumatic stress disorder during script-driven imagery. Biol Psychiatry. 2005;57(8):832-40.
40. Bruce SE, Buchholz KR, Brown WJ, Yan L, Durbin A, Sheline YL. Altered emotional interference processing in the amygdala and insula in women with post-traumatic stress disorder. Neuroimage Clin. 2013; 2:43-9.

41. Vermetten E, Schmahl C, Southwick SM, Bremner JD. Positron tomographic emission study of olfactory induced emotional recall in veterans with and without combat-related posttraumatic stress disorder. Psychopharmacol Bull. 2007:40(1):8-30.

42. Tawakol A, Ishai A, Takx RAP, Figueroa AL, Ali A, Kaiser Y, Truong QA, Solomon CJE, Calcagno C, Mani V, et al. Relation between resting amygdalar activity and cardiovascular events: a longitudinal and cohort study. Lancet. 2017;389(10071):834-45.

43. Bremner JD, Campanella C, Khan Z, Fani N, Kasher N, Evans S, Reiff C, Mishra S, Ladd S, Nye JA, et al. Brain mechanisms of stress and depression in coronary artery disease. J Psychiatr Res. 2019;109:76-88.

44. Bremner JD, Soufer R, McCarthy G, Delaney RC, Staib LH, Duncan JS, Charney DS. Gender differences in cognitive and neural correlates of remembrance of emotional words. Psychopharmacol Bull. 2001;35:55-87.

45. Stevens JS, Hamann S. Sex differences in brain activation to emotional stimuli: a meta-analysis of neuroimaging studies. Neuropsychologia. 2012; 50(7):1578-93.

46. Wager TD, Phan KL, Liberzon I, Taylor SF. Valence, gender, and lateralization of functional brain anatomy in emotion: a meta-analysis of findings from neuroimaging. Neuroimage. 2003;19(3):513-31.

47. Hammadah M, Al Mheid I, Wilmot K, Ramadan R, Shah AJ, Sun Y, Pearce B, Garcia EV, Kutner M, Bremner JD, et al. The Mental Stress Ischemia Prognosis Study (MIPS): Objectives, study design, and prevalence of inducible ischemia. Psychosom Med. 2017;79(3):311-7.

48. Lanius RA, Brewin CR, Bremner JD, Daniels JK, Friedman MJ, Liberzon I, McFarlane A, Schnurr PP, Shin L, Stein M, et al. Does neuroimaging research examining the pathophysiology of posttraumatic stress disorder require medication-free patients? J Psychiatry Neurosci. 2010; 35(2):80-9.

49. First MB, Spitzer RL, Williams JBW, Gibbon M. Structured Clinical Interview for DSMIV-Patient Edition (SCID-P). Washington, D.C.: American Psychiatric Press; 1995.

50. Bremner JD, Vythilingam M, Vermetten E, Adil J, Khan S, Nazeer A, Afzal N, McGlashan T, Anderson G, Heninger GR, et al. Cortisol response to a cognitive stress challenge in posttraumatic stress disorder (PTSD) related to childhood abuse. Psychoneuroendocrinology. 2003;28:733-50.

51. Weinhard K, Schmand M, Casey ME, Baker K, Bao J, Eriksson L, Jones WF, Knoess C, Lenox M, Lercher $M$ et al: The ECAT HRRT: performance and first clinical application of the new high resolution research tomograph. IEEE Trans Med Imaging 2000, 3(Nuclear Science Symposium Conference Record):17/12-17/16.

52. Bremner JD, Vythilingam M, Vermetten E, Southwick SM, McGlashan T, Nazeer A, Khan S, Vaccarino LV, Soufer R, Garg P, et al. MRI and PET study of deficits in hippocampal structure and function in women with childhood sexual abuse and posttraumatic stress disorder (PTSD). Am J Psychiatry. 2003;160(5):924-32.

53. Bremner JD, Narayan M, Staib LH, Southwick SM, McGlashan T, Charney DS. Neural correlates of memories of childhood sexual abuse in women with and without posttraumatic stress disorder. Am J Psychiatry. 1999;156:1787-95.

54. Talairach J, Tournoux P. Co-planar stereotaxic atlas of the human brain: 3dimensional proportional system, an approach to cerebral imaging. Stuttgart: Georg Thieme; 1988.

55. Lane RD, Reiman EM, Ahern CE, Schwartz GE, Davidson RJ. Neuroanatomical correlates of happiness, sadness, and disgust. Am J Psychiatry. 1997;154:926-33.

56. Gläscher J, Gitelman D. Contrast weights in flexible factorial design with multiple groups of subjects. SPM@ JISCMAIL AC UK. 2008:1-12.

57. Vogt BA, Finch DM, Olson CR. Functional heterogeneity in cingulate cortex: the anterior executive and posterior evaluative regions. Cereb Cortex. 1992;2:435-43.

58. Devinsky O, Morrell MJ, Vogt BA. Contributions of anterior cingulate to behavior. Brain. 1995;118:279-306.

59. Quirk GJ. Memory for extinction of conditioned fear is long-lasting and persists following spontaneous recovery. Learn Memory. 2002;9:402-7.

60. Milad MR, Rauch SL, Pitman RK, Quirk GJ. Fear extinction in rats: implications for human brain imaging and anxiety disorders. Biol Psychol. 2006;73(1):61-71. 
61. Milad MR, Quirk GJ. Neurons in medial prefrontal cortex signal memory for fear extinction. Nature. 2002;420:70-3.

62. Quirk GJ, Likhtik E, Pelletier JG, Pare D. Stimulation of medial prefrontal cortex decreases the responsiveness of central amygdala output neurons. J Neurosci. 2003;23:8800-7.

63. Radley JJ, Sisti HM, Hao J, Rocher AB, McCall T, Hof PR, McEwen BS, Morrison JH. Chronic behavioral stress induces apical dendritic reorganization in pyramidal neurons of the medial prefrontal cortex. Neuroscience. 2004;125(1):1-6.

64. Diener C, Kuehner C, Brusniak W, Ubl B, Wessa M, Flor H. A meta-analysis of neurofunctional imaging studies of emotion and cognition in major depression. Neuroimage. 2012;61(3):677-85.

65. Vaccarino V, Votaw J, Faber T, Veledar E, Murrah NV, Jones LR, Zhao J, Su S, Goldberg J, Raggi JP, et al. Major depression and coronary flow reserve detected by positron emission tomography. Arch Intern Med. 2009;169:1668-76.

66. Vaccarino V, Goldberg J, Rooks C, Shah AJ, Veledar E, Faber TL, Votaw JR, Forsberg CW, Bremner JD. Post-traumatic stress disorder and incidence of coronary heart disease: a twin study. J Am Coll Cardiol. 2013;62(11):97-978

67. Campanella C, Bremner JD. Neuroimaging of PTSD. In: Bremner JD, editor Posttraumatic Stress Disorder: From Neurobiology to Treatment. Hoboken: Wiley-Blackwell; 2016. p. 291-320.

68. Bremner JD. Changes in brain volume in major depression. Depression. 2005;2(2):38-46

69. Mayberg HS, Brannan SK, Mahurin RK, Jerabek PA, Brickman JS, Tekell $J$, Silva JA, McGinnis S, Glass TG, Martin CC, et al. Cingulate function in depression: a potential predictor of treatment response. Neuroreport. 1997:8:1057-61.

70. Soufer R, Bremner JD, Arrighi JA, Cohen I, Zaret BL, Burg MM, Goldman-Rakic P. Cerebral cortical hyperactivation in response to mental stress in patients with coronary artery disease. Proc Natl Acad Sci U S A. 1998;95:6454-9.

71. Beissner F, Meissner K, Bar KJ, Napadow V. The autonomic brain: an activation likelihood estimation meta-analysis for central processing of autonomic function. J Neurosci. 2013;33(25):10503-11.

72. Adamaszek M, D'Agata F, Ferrucci R, Habas C, Keulen S, Kirkby KC, Leggio M, Mariën P, Molinari M, Moulton E, et al. Consensus paper: cerebellum and emotion. Cerebellum. 2017;16(2):552-76.

73. Leiner HC, Leiner AL, Dow RS. Reappraising the cerebellum: what does the hindbrain contribute to the forebrain? Behav Neurosci. 1989;103(5):998-1008.

74. Buckner RL, Andrews-Hanna JR, Schacter DL. The brain's default network: anatomy, function, and relevance to disease. Ann N Y Acad Sci. 2008:1124:1-38.

75. Yang Y, Zhong N, Friston K, Imamura K, Lu S, Li M, Zhou H, Wang H, Li K, $\mathrm{Hu}$ B. The functional architectures of addition and subtraction: network discovery using fMRI and DCM. Hum Brain Mapp. 2017;38(6):3210-25.

76. Deschamps I, Baum SR, Gracco VL. On the role of the supramarginal gyrus in phonological processing and verbal working memory: evidence from rTMS studies. Neuropsychologia. 2014;53:39-46.

77. Frank DW, Dewitt M, Hudgens-Haney M, Schaeffer DJ, Ball BH, Schwarz NF, Hussein AA, Smart LM, Sabatinelli D. Emotion regulation: quantitative metaanalysis of functional activation and deactivation. Neurosci Biobehav Rev. 2014;45:202-11.

78. Vigneau M, Beaucousin V, Herve PY, Duffau H, Crivello F, Houde O, Mazoyer B, Tzourio-Mazoyer N. Meta-analyzing left hemisphere language areas: phonology, semantics, and sentence processing. Neuroimage. 2006;30(4):1414-32.

79. Ardila A, Bernal B, Rosselli M. Language and visual perception associations: meta-analytic connectivity modeling of Brodmann area 37. Behav Neurol. 2015;2015:565871.

80. Karhson DS, Mock JR, Golob EJ. The role of right inferior parietal cortex in auditory spatial attention: a repetitive transcranial magnetic stimulation study. PLoS One. 2015;10(12):e0144221.

81. Wager TD, Smith EE. Neuroimaging studies of working memory: a metaanalysis. Cogn Affect Behav Neurosci. 2003;3(4):255-74.

82. Van Ettinger-Veenstra H, Ragnehed M, McAllister A, Lundberg P, Engstrom M. Right-hemispheric cortical contributions to language ability in healthy adults. Brain Lang. 2012;120(3):395-400.

83. Lanzilotto M, Perciavalle $V$, Lucchetti C. Auditory and visual systems organization in Brodmann Area 8 for gaze-shift control: where we do not see, we can hear. Front Behav Neurosci. 2013;7:198.

84. Kessler RC, Berglund P, Demler O, Jin R, Koretz D, Merikangas KR, Rush AJ Walters EE, Wang PS. The epidemiology of major depressive disorder: results from the National Comorbidity Survey Replication (NCS-R). J Am Med Assoc 2003;289:3095-105.
85. Lewis TT, Guo H, Lunos S. Mendes de Leon CF, Skarupski KA, Evans DA, Everson-Rose SA: Depressive symptoms and cardiovascular mortality in older black and white adults: evidence for a differential association by race. Circ Cardiovasc Qual Outcomes. 2011;4(3):293-9.

\section{Publisher's Note}

Springer Nature remains neutral with regard to jurisdictional claims in published maps and institutional affiliations.
Ready to submit your research? Choose BMC and benefit from:

- fast, convenient online submission

- thorough peer review by experienced researchers in your field

- rapid publication on acceptance

- support for research data, including large and complex data types

- gold Open Access which fosters wider collaboration and increased citations

- maximum visibility for your research: over $100 \mathrm{M}$ website views per year

At BMC, research is always in progress.

Learn more biomedcentral.com/submissions 